\title{
Processos de perda, luto e a assistência da Terapia Ocupacional nas situaçóes de escalpelamento
}

\author{
Andreza Mouráo Lopes ${ }^{a}$, Victor Augusto Cavaleiro Corrêa ${ }^{b}$ \\ aTerapeuta ocupacional, mestranda em Psicologia, Universidade Federal do Pará - UFPA, Belém, PA, Brasil

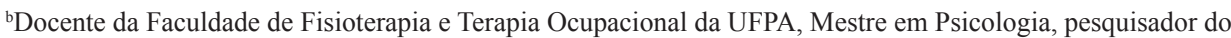 \\ Laboratório de Estudos do Luto e Saúde - LAELS, Universidade Federal do Pará - UFPA, Belém, PA, Brasil
}

\begin{abstract}
Resumo: Esta pesquisa objetivou compreender os processos de perda, luto e a assistência do terapeuta ocupacional junto a uma criança em situação de escalpelamento e hospitalização. Trata-se de uma pesquisa qualitativa, do tipo estudo de caso. Participou da pesquisa uma criança de 8 anos de idade, do sexo feminino e vítima de escalpelamento. Os resultados revelaram que o escalpelamento repercutiu em inúmeras mudanças e rupturas no cotidiano da criança participante, gerando alterações significativas, como a perda dos cabelos e partes da pele da face. A criança foi internada, ficando afastada das atividades ocupacionais, como estudar, brincar, entre outras. Foi observada a expressão de sentimentos como medo, vergonha, ansiedade, tristeza, gerados pela perda dos cabelos. Desse modo, acredita-se que a realização da intervenção apresentou grande relevância, pois permitiu o contato com a temática tão característica da região Norte do Brasil, assim como a percepção e o esclarecimento sobre a importância da assistência da Terapia Ocupacional proporcionando um espaço de expressão e a ressignificação dos fazeres, oportunizando o retorno dessa criança às suas atividades ocupacionais significativas.
\end{abstract}

Palavras-chave: Criança, Hospitalização, Terapia Ocupacional.

\section{Loss and grief process and Occupational Therapy assistance in scalping situations}

\begin{abstract}
In this research, we aimed to understand the loss and grief process and the occupational therapy assistance to a hospitalized child undergoing a scalping situation. It is a case study of qualitative approach. This survey was carried out with the participation of an 8-year-old female scalping victim. Results revealed that the scalping caused many changes such as loss of hair and parts of the facial skin. The child was hospitalized, staying away from occupational activities such as studying, playing, among others. We observed the expression of feelings such as fear, shame, anxiety and sadness generated by hair loss. Thus, we believe that this research is of high relevance because it allowed contact with a theme so characteristic of northern Brazil, as well as with the perception and clarification about the importance of occupational therapy assistance in providing space for expression and reframing of the doings, giving the opportunity to this child to resume her significant occupational activities.
\end{abstract}

Keywords: Child, Hospitalization, Occupational Therapy.

\footnotetext{
Autor para correspondência: Victor Augusto Cavaleiro Corrêa, Universidade Federal do Pará, Setor Profissional, Saúde, Faculdade de Fisioterapia e Terapia Ocupacional, Rua Augusto Corrêa, 01, Belém, PA, Brasil, e-mail: victorcavaleiro@gmail.com Recebido em 17/8/2011; Revisão em 12/12/2011; Aceito em 25/1/2012.
} 


\section{Introdução}

Esta pesquisa objetivou compreender os processos de perda e luto junto a uma criança em situação de escalpelamento e hospitalizaçáo e a assistência da terapia ocupacional. O escalpelamento é um fenômeno que acomete as comunidades ribeirinhas ${ }^{1}$ da Amazônia. Consiste no arrancamento brusco, parcial ou total, do couro cabeludo, ocasionado em acidentes por motores e hélices de pequenas embarcaçôes, devido à falta de proteção do eixo. $\mathrm{O}$ acidente ocorre quando as vítimas, ao se aproximarem do motor ou das hélices, têm seus cabelos enroscados e puxados pelo eixo do motor dessas embarcaçôes. A forte rotação ininterrupta do motor enrola os cabelos em torno do eixo e arranca todo ou parte do escalpo $^{2}$ da vítima, inclusive orelhas, sobrancelhas e, por vezes, uma enorme parte da pele do rosto e do pescoço, levando a deformaçóes graves e até à morte, devido à intensa hemorragia (BRITTO et al., 2004). Nesse contexto, destacam-se as crianças, que, com o longo período de internação, têm suas vidas modificadas, lidam com situaçóes de intensa dor, perdem partes do corpo, afastam-se das localidades onde moram, ficando distantes da convivência com os familiares e amigos.

A assistência à saúde nesses casos geralmente é longa e dolorosa. A primeira etapa é repor a pele do crânio com enxertos ${ }^{3}$ retirados das pernas. Os médicos também recorrem ao expansor, uma espécie de bolsa ou prótese que é colocada por baixo da pele do paciente. Essa prótese recebe soro fisiológico e vai enchendo. O objetivo é esticar, aumentar ou expandir a pele (MOTTA, 2003).

A assistência ao escalpelamento encontra-se intrinsecamente relacionado ao processo da hospitalização, que segundo Takatori, Oshiro e Otashima (2004) traz para o paciente a experiência de vivenciar a dor, além de situaçôes que favorecem o afastamento da família, a qual, por sua vez, também passa por situaçóes de incerteza, tensão, medo, angústia e dor, decorrente da gravidade das lesôes.

O período de internaçáo nos casos de escalpelamento dura, em média, 90 dias. Durante o tratamento, essas pessoas necessitam de atendimento dos profissionais, principalmente de médicos, enfermeiros, psicólogos, nutricionistas, fisioterapeutas, assistentes sociais e terapeutas ocupacionais. Vale ressaltar a importância da equipe multiprofissional para atenuar a sintomatologia álgica, prevenção de deformidades e/ou contraturas e para favorecer suporte emocional, social e ocupacional a essas pessoas (MOTTA, 2003).
O processo de hospitalização gera inúmeras mudanças e rupturas de suas relaçóes e de seu cotidiano. Experimentam-se o sofrimento, a solidão, a dependência dos outros, o medo, o encontro com as limitaçóes, entre outras. No hospital, as regras, os horários, a convivência com os demais pacientes, com profissionais da saúde, dentre tantas outras situaçóes, são experiências vivenciadas rotineiramente. A hospitalização, independente da gravidade da doença, é um processo que causa medo e insegurança. Para Silva (1992, p. 6):

a hospitalização, por mais simples que seja o motivo, tende a levar a uma experiência negativa. O desconforto físico, moral, espiritual e o medo da morte podem gerar sofrimentos.

Segundo Takatori, Oshiro e Otashima (2004), a criança vivencia uma realidade desconhecida no ambiente hospitalar; é difícil compreender a necessidade de estar em um lugar diferente, ao lado de pessoas estranhas. A criança escuta o som dos equipamentos hospitalares que parece anunciar um novo procedimento - mais uma punção, injeção de medicação, troca de soro, medição da pressão e da temperatura, troca de curativo etc. Da colocaçáo do termômetro à sonda, dependendo de como o procedimento é realizado, tudo pode ser sentido como invasivo ou doloroso para a criança. As paredes do quarto, a comida e os sons diferentes. Enfim, a hospitalização é uma experiência estressante que envolve profunda adaptação da criança às várias mudanças que acontecem em seu dia a dia.

Para Bowlby (1993), a hospitalização da criança é vista como uma situação crítica e delicada tanto para ela e/ou para a família, quanto para a equipe hospitalar. Durante a internação, vários fatores adversos estáo presentes, como mudança do ambiente físico e psicológico, separação dos pais e demais familiares, interrupção das atividades cotidianas, entre outros. A hospitalização é uma das situações que envolvem profunda adaptação do homem às várias mudanças que acontecem no seu dia a dia.

Nesse contexto, destaca-se a necessidade de uma compreensão biopsicossocial pela equipe de saúde, visto que tal olhar proporciona uma visão integral do ser e do adoecer que compreende as dimensóes física, psicológica, social, cultural, espiritual, ocupacional, entre outras, considerando a saúde como fruto de uma combinação de fatores, abarcando aspectos relativos ao corpo, mente e ao ambiente em que a pessoa esteja inserida (MARCO, 2003; ENGEL 1192 apud GRILO, 2004; CASTRO, 2007). Então, o ser humano é visto como um ser multidimensional, com o estado de saúde contínuo. No caso das crianças em 
situação de escalpelamento, destacam-se a perda dos cabelos, o afastamento da família e do cotidiano, fatos que ocasionavam na criança sentimentos de tristeza, isolamento, solidão, culpa, medo, rompimentos, mudanças, entre outros sentimentos característicos dessas crianças quando ingressavam no hospital.

Esse contexto impulsionou compreender como o terapeuta ocupacional poderia contribuir nas situaçôes que envolviam o escalpelamento, destacando uma assistência para expressão das perdas e luto nesses casos.

\subsection{Caminho metodológico da pesquisa}

Nesta pesquisa, optou-se por uma análise com abordagem metodológica qualitativa do tipo estudo de caso. A abordagem ou pesquisa qualitativa é um processo de reflexão e análise da realidade através $\mathrm{da}$ utilização de métodos e técnicas para a compreensão detalhada do objeto de estudo em seu contexto histórico e/ou segundo sua estruturação, em que o conhecimento não se reduz a um conjunto de dados isolados conectados por uma teoria explicativa. Essa abordagem atenta para as particularidades, para a profundidade do conhecimento do objeto de estudo, imerso em um determinado contexto social, com suas crenças, costumes, valores e significados (OLIVEIRA, 2000; CHIZZOTTI, 2001; MARTINS; BICUDO, 2003; TURATO, 2003; ROCHA; BRUNELLO, 2007; OLIVEIRA, 2007; MINAYO, 2008). Abrange um processo de percepçáo e reflexão do objeto de estudo, em que os instrumentos e técnicas são construídos para a compreensão detalhada do interesse e/ou do objeto do estudo em um contexto histórico.

O estudo de caso consiste na análise profunda e exaustiva de um ou poucos objetos de investigação, de maneira que permita seu amplo e detalhado conhecimento. É uma categoria de pesquisa cujo objeto é uma unidade que se analisa profundamente. Visa conhecer o seu "como" e os seus "porquês", evidenciando a sua unidade e identidade própria. É uma investigação que se assume como particularística, debruçando-se sobre uma situação específica, procurando descobrir o que há nela de mais essencial e característico (YIN, 2001; VENTURA, 2007). De forma geral, o estudo de caso visa proporcionar uma vivência da realidade, tendo por base a discussão, a análise e a busca de solução de um determinado problema. Em verdade, trata-se de uma estratégia metodológica de amplo uso, quando se pretende responder às questóes "como" e "por que" determinadas situaçóes ou fenômenos ocorrem, principalmente quando se dispóem de poucas possibilidades de interferência ou de controle sobre os eventos estudados.

\subsection{Local e participante da pesquisa}

A pesquisa foi desenvolvida na Fundação Santa Casa de Misericórdia do Pará (FSCMPA). Dentre os atendimentos prestados pela instituição, destaca-se o Programa de Atendimento Integral às Vítimas de Escalpelamento - Paives (PARÁ, 2008). Participou desta pesquisa uma criança de 8 anos de idade, que sofreu escalpelamento e esteve hospitalizada entre os meses de dezembro de 2009 e março de 2010 na enfermaria pediátrica da Fundação Santa Casa de Misericórdia do Pará e que aceitou participar da pesquisa. A criança participante estava recém-internada e apresentava o menor período de internação, visto que o objetivo desta pesquisa era o acompanhamento da criança desde o início do processo de hospitalizaçáo. Foram excluídas do estudo as crianças que estiveram fora da faixa etária (4 aos 12 anos) determinada e fossem acometidas de outras patologias. Para efeito de sigilo, as participantes deste estudo foram identificadas através dos respectivos nomes fictícios: a criança foi chamada de Jasmim devido ao significado de delicadeza e a mãe de Íris por significar proteção.

\subsection{Procedimentos de coleta e análise dos dados}

A pesquisa foi desenvolvida respeitando a integridade física e psíquica das pessoas participantes, respeitando as Normas de Pesquisa envolvendo Seres Humanos (Res. CNS 196/96) do Conselho Nacional de Saúde (1996), após aprovaçáo do Comitê de Ética em Pesquisa da Fundação Santa Casa de Misericórdia do Pará, da autorização da direção da unidade e dos pacientes, por meio do Termo de Consentimento Livre Esclarecido (TCLE).

Após a aprovação do projeto pelo Comitê de Ética, foram consultados os prontuários das crianças em situação de escalpelamento que se encontravam hospitalizadas na pediatria da instituição. Após a seleçáo, foi realizado o primeiro encontro com a criança e com sua mãe, a fim de estabelecer o primeiro contato, apresentar os objetivos da pesquisa e de obter a autorização quanto à participação da paciente na pesquisa, por meio do TCLE. Foram propostos dois encontros semanais com duração de 40 a 60 minutos, durante dois meses, a fim de que a criança brincasse com o intuito de expressar o que estivesse pensando e sentindo. 
Nos primeiros encontros, foram realizadas entrevistas semidirigidas. O primeiro encontro serviu para colher informaçóes acerca da identificação e sobre a vida da criança, através da seguinte pergunta: "Agora, após a explicação dos objetivos da pesquisa e leitura do Termo de Consentimento, gostaria que você falasse sobre a vida de sua filha". No segundo encontro, foram colhidas informações sobre a criança no contexto do hospital, através do seguinte questionamento: "Neste segundo encontro, gostaria que você contasse como está sua filha no hospital".

Posteriormente, a criança passou a ser atendida no espaço da brinquedoteca, em que foi favorecido o brincar livre, através da exploração dos objetos de maneira espontânea. Para registro das informaçóes coletadas, os encontros foram gravados e filmados, com a utilização de câmera digital. Além disso, foi utilizado um diário de campo para registro das intervençôes (falas, ações e reações, no momento dos atendimentos) que eram discutidas e analisadas após o término de cada encontro.

\section{O caso de Jasmim e sua experiência no escalpelamento e na hospitalização}

Jasmim era uma criança de 8 anos de idade, nascida em 31 de março de 2001, de parto normal na cidade de Itaituba ${ }^{4}$. Morava com a mãe, o irmão e o padrasto em uma casa simples, nos fundos da casa dos pais de seu padrasto, os quais a criança considera como avós. Jasmim residia em uma comunidade no interior da cidade de Itaituba, PA e sempre deslocava-se para a capital para visitar alguns familiares.

No dia 3 de novembro de 2009, aos 8 anos de idade, Jasmim sofreu um acidente, quando viajava em uma embarcação de pequeno porte, que transportava, além dela, a mãe, o irmão e outras pessoas. Segundo relatos de Íris, durante essa viagem Jasmim deitou-se sobre um pedaço de madeira localizado logo acima do eixo do motor, apoiando-se em um salva-vidas5. Contou que permaneceu nessa posição por 10 minutos. Nesse período, seus cabelos foram enroscados e puxados pelo eixo do motor da embarcação. Nesse momento referiu que houve um barulho no barco e Jasmim levantou-se e, sangrando muito, mostrou o ferimento para sua mãe, que enfaixou sua cabeça com panos e permaneceram no barco durante 4 horas, até chegar ao hospital mais próximo.

Ao chegar ao hospital, a criança foi submetida a curativos, realizou exames e fez uso de medicação.
Segundo relatos da mãe, Jasmim ficou hospitalizada durante 10 dias. Percebia-se que esse período de hospitalização caracterizou para Jasmim intenso sofrimento e medo dos procedimentos invasivos, assim como receio dos profissionais de saúde.

Com a alta hospitalar, Jasmim permaneceu em casa durante 15 dias, quando uma vizinha, que também havia sofrido o acidente alguns anos antes, teve conhecimento de seu acidente e informou à Marinha do Brasil, que ofereceu a passagem para que Jasmim fosse a Belém para assistência especializada, na Fundação Santa Casa de Misericórdia do Pará.

Nos primeiros dias de internação na Fundação Santa Casa, Jasmim mostrou-se retraída e apreensiva em relação à situação que ela iria vivenciar a partir daquele momento, visto que a primeira hospitalizaçáo havia sido traumática para ela, em função dos procedimentos e curativos necessários nos primeiros cuidados. Essa segunda internação era compreendida por Jasmim como uma nova situação de estresse. Jasmim relatava: "Aquele hospital era horrivel, eles me tratavam mal".

Inicialmente, Jasmim foi escolhida para a pesquisa por ser a primeira criança vítima de escalpelamento a dar entrada no hospital, após a aprovação do projeto de pesquisa no Comitê de Ética da referida instituição.

No primeiro contato com Jasmim, a pesquisadora sentiu ansiedade e medo. Havia uma inquietação de como seria a reação da criança ao conhecê-la, visto que Jasmim poderia sentir-se incomodada com a presença da terapeuta ocupacional além da preocupação se haveria ou não a realização de vínculo entre Jasmim e a terapeuta ocupacional.

Ao deparar-se com a criança, percebeu-se que, nos primeiros momentos, Jasmim sentiu-se envergonhada, tímida e temerosa. Já a mãe demonstrou-se colaborativa e atenciosa. Na presença de sua genitora, Jasmim conversou com a terapeuta ocupacional, relatando seu nome, idade, endereço, assim como suas atividades, brincadeiras e brinquedos favoritos. Contou que gostava de tomar banho de rio, brincar com o irmáo, gostava de suas bonecas e de ursos de pelúcia. Dizia: "Eu adoro meu bichinho, ele é meu amigo". Nesses primeiros instantes, já era possível perceber que Jasmim sentia-se à vontade, tornando a relaçáo mais próxima e acolhedora.

Em um segundo contato, Jasmim mostrou-se comunicativa, relatou sobre o acidente que sofreu, comentando detalhes, como o dia, o horário, o local e que não havia sentido dor no momento do trauma. Nesses momentos, Jasmim convidava para participar do brincar. Contava que sentia dor durante 
a realizaçáo dos procedimentos e que as outras crianças olhavam para ela de maneira diferente na escolinha do hospital.

Os primeiros contatos com Jasmim foram extremamente importantes para a realização dos atendimentos seguintes. Era possível perceber que a mesma apresentava dificuldade em relacionar-se com a equipe de saúde do hospital, mantendo-se retraída e restrita ao leito. Jasmim reagia com desconfiança ao contato com os profissionais, duvidosa de como seriam os procedimentos realizados.

No decorrer dos encontros, Jasmim demonstrava-se envergonhada, triste e sem vontade de frequentar espaços como a brinquedoteca; porém, quando convidada para realizar alguma atividade, demonstrava interesse. Esse era um momento em que se valorizava a singularidade de Jasmim, em que sua autonomia e independência eram favorecidas, possibilitando-lhe ser ativa em suas decisóes e em suas demandas individuais. Buscava-se realizar as atividades de sua preferência, onde ela conduzia os atendimentos de acordo com suas necessidades naquela circunstância. Jasmim sentia-se à vontade para expressar seus sentimentos.

Antes da hospitalização, Jasmim possuía hábitos, frequentava a escola, ajudava a mãe nas tarefas de casa e tomava banho de rio. Com as mudanças decorrentes do acidente e da hospitalização, Jasmim encontrava-se incomodada com a rotina do hospital; suas atividades do dia a dia passaram a ser curativos e visitas de profissionais em seu leito. Preferia voltar para casa e realizar suas atividades de costume, dizia que o hospital era muito "chato". Jasmim afastou-se das atividades que costumava fazer, como o brincar, pois o contexto hospitalar implicava na restrição ao leito, na realizaçáo de procedimentos e nas visitas dos profissionais de saúde.

Através da utilização de bonecas e ursos de pelúcia, o brincar de "faz-de-conta" era um estímulo à criatividade e à percepção de aspectos positivos da hospitalização. Em um determinado atendimento, uma boneca foi utilizada em uma brincadeira de médico, onde Jasmim pôde realizar alguns procedimentos invasivos do contexto hospitalar, experiências, geralmente, vividas no hospital. Ao término dessa atividade, Jasmim solicitou o empréstimo da boneca, que permaneceu durante um longo período em sua enfermaria. Na boneca, Jasmim brincava de realizar procedimentos como: curativos, ausculta, verificava a pressão arterial, colocava roupa, bijuterias etc.

A boneca era utilizada para exemplificar os procedimentos que seriam realizados durante a cirurgia. Foi explicado a Jasmim que seria retirado um pedacinho de "pele" da perna da boneca para cobrir uma "feridinha" na cabeça da mesma. Nessa circunstância, Jasmim ficou entristecida, perguntou como ficaria a perna da boneca. Jasmim buscava esclarecer o procedimento cirúrgico, aplicando na boneca todos os passos da cirurgia. Brincando, a criança entrava em contato com os procedimentos e conhecia o desconhecido.

Quanto ao procedimento cirúrgico de Jasmim, percebeu-se que nos dias antecedentes a criança demonstrava-se bastante nervosa e ansiosa devido ao procedimento, expressava o desejo de sair do hospital. Jasmim, afirmava sua vontade de voltar para sua casa, de tomar banho de rio e de brincar com o irmáo. Nesses momentos, oportunizava-se a Jasmim manifestar seus desejos, sentimentos, vontades, saudades, dentre outros.

Acredita-se que a criança, através de suas falas, exprimia a necessidade de sentir-se segura diante do desconhecido - a cirurgia. Apresentava-se ansiosa quanto à ausência do seu lar e de suas individualidades culturais. Nesses momentos, ofertava-se um espaço para a expressão. Entende-se que através dessa intervenção era possível auxiliar Jasmim no enfrentamento quando do procedimento cirúrgico como etapa do tratamento; valorizavam-se aspectos positivos do mesmo, possibilitando a Jasmim segurança nesses momentos.

Jasmim expressava medo quanto ao procedimento cirúrgico, através de choro, assim como se sentia envergonhada em frequentar a brinquedoteca, devido aos curativos. Vivia conflitos em relação às perdas e às mudanças decorrentes do acidente e das cirurgias.

Após a realização da cirurgia, Jasmim mostrou desinteresse em frequentar o espaço da brinquedoteca. Dizia: "[...] não quero ir pra lá, vão ficar olhando pra mim". Jasmim demonstrava estar totalmente incomodada com a sua aparência, pois estava com curativos na cabeça e na perna esquerda. Acreditava que os outros pacientes a rejeitariam devido aos seus curativos. Demonstrava medo quanto ao afastamento dos outros pacientes. Nesses momentos, o brincar auxiliava na socialização e na interação de Jasmim com outras crianças, permitindo que ela pudesse sair do isolamento de sua enfermaria e entrar em contato com o contexto hospitalar em que se encontrava. Proporcionava que Jasmim pudesse estabelecer contato com as demais pessoas no hospital.

Enfim, Jasmim enfrentou uma situação de distanciamento de seu cotidiano e, principalmente, de suas ocupaçóes mais significativas, pois a hospitalização aconteceu de forma inesperada e 
prolongou-se por um longo período. Nesse sentido, os momentos com Jasmim foram uma possibilidade de brincar de maneira espontânea, em que ela podia expressar o que estivesse sentindo, sendo possível, em um primeiro momento, perceber medo e ansiedade quanto aos profissionais da saúde, os curativos e principalmente do procedimento cirúrgico e, posteriormente, um espaço de descobertas para Jasmim, possibilitando seu engajamento e novos fazeres.

\section{Sobre o escalpelamento e a hospitalizaçao de Jasmim: processo de perda e luto}

Não é difícil imaginar o que significa um ferimento como o escalpelamento para as jovens vítimas e suas famílias. A maioria não apenas sobrevive ao acidente como carrega consigo as marcas físicas e psíquicas, mesmo após extenso período de tratamento. A avulsão de couro cabeludo ocasionou repercussóes muito graves, tanto pela lesão físico-orgânica quanto pelas consequências biopsicossociais e ocupacionais que decorreram do acidente. Jasmim experienciou a perda dos cabelos, o distanciamento da família, da escola, dos amigos, entre outros fazeres do dia a dia. Sofreu modificaçóes no seu contexto de vida, manifestando, inicialmente, isolamento, resistência com a equipe multiprofissional do hospital e a restrição ao leito.

Jasmim, antes do acidente, era uma criança ativa, brincante, estudante e, entre outras ações, explorava, agia e modificava seu contexto. Durante a hospitalização, encontrava-se restrita ao leito do hospital, espectadora e manifestando limitaçóes para brincar e explorar o meio.

A identidade de ser criança é, muitas vezes, diluída numa situação de internação, em que a criança se vê numa realidade diferente da sua vida cotidiana. O papel de ser criança é sufocado pelas rotinas e práticas hospitalares que tratam a criança como paciente, como aquele que inspira e necessita de cuidados médicos, que precisa ficar imobilizado e que aparece alheio aos acontecimentos ao seu redor (FONTES, 2005, p. 119).

$\mathrm{Na}$ perspectiva do cliente que necessita de internação hospitalar, percebe-se o medo do desconhecido; como a utilização de recursos tecnológicos, muitas vezes invasivos, linguagem técnica e rebuscada, o ambiente estranho, e ainda pela preocupação com sua integridade física, em decorrência do processo patológico, motivo de sua internação hospitalar (TAKATORI; OSHIRO; OTASHIMA, 2004).

Carvalho e Begnis (2006) afirmam que os prejuízos que a hospitalização pode causar à criança estáo ligados ao fato de que, durante a internação, a criança está afastada de seu ambiente familiar, de sua vida escolar e às vezes privada da companhia dos pais. Além disso, a criança pode ser exposta a procedimentos dolorosos, invasivos e desagradáveis. Dessa forma, a internação causava um impacto no estado psíquico da criança, podendo gerar um trauma.

Nunes (2003) mostra que a hospitalização ganha novas dimensóes no contexto existencial desse paciente e pode provocar diversos sentimentos, como frustração, hostilidade, culpa, negação, impotência, regressão, dependência, ansiedade, desconfiança, fobias, insegurança, desamparo, depressão, entre outros.

A hospitalização também pode ser sentida como uma morte, envolvendo algumas perdas, como mudança de ambiente, afastamento da família, dos amigos, a perda da privacidade, da autonomia e solidão, mesmo no meio de muitos "estranhos". Um contexto de perdas, em que a pessoa "fazia", "podia", "estava" (OTHERO, 2010). O medo do sofrimento e da dor pode fazer com que a pessoa se sinta morta ou prefira a morte a viver com limitaçôes e medos (BROMBERG, 2000).

Segundo Othero (2010), a ruptura do cotidiano ocasionada pelo processo de adoecimento ocorre de forma brusca, com transformações físicas, emocionais e sociofamiliares, podendo levar a pessoa a dificuldades e à necessidade de adaptaçóes, comprometendo a qualidade e a organização das atividades do dia a dia. Jasmim encontrava-se diante da perda de sua rotina e de seus hábitos, como frequentar a escola, ajudar a mãe nas tarefas de casa e tomar banho de rio. Com o cotidiano alterado, a criança encontrava-se desadaptada à rotina do hospital, pois suas atividades do dia a dia passaram a ser curativos e visitas de profissionais em seu leito. Jasmim, em vários momentos, referia o seu desejo de voltar para casa e realizar suas atividades de costume, dizendo: "o hospital é muito chato".

No trabalho com crianças hospitalizadas, Lindquist (1993) escreveu sobre a presença de comportamentos que surgem rotineiramente em um processo de hospitalização, como, por exemplo, a modificação na dinâmica familiar, a interrupção ou o retardo da escolaridade, as carências afetivas, a privação materna, as agressões físicas e psicológicas. Nesse contexto, as perdas significativas, como a dos cabelos, o afastamento do 
cotidiano e da família, em decorrência do acidente e a necessidade de hospitalização, requeriam da criança um reajustamento social e ocupacional, uma mudança de vida, a partir de um evento, não importando o quanto foi desejado ou náo. A perda dos cabelos, o afastamento do cotidiano e da família, requereu de Jasmim um reajustamento social, uma mudança da rotina de vida.

O sentimento da perda é um sentimento de desamparo. Uma lacuna, uma falha, que nenhuma outra pessoa pode sentir igual, já que é um processo singular. Com as repercussóes do escalpelamento, Jasmim demonstrou desinteresse em desempenhar suas funçôes ocupacionais devido ao processo de perdas no qual se encontrava. Seus sentimentos estiveram confusos dentro de um novo contexto. Jasmim experienciou um processo de luto que era expresso nos momentos de intervenção.

Segundo Bromberg (1994) e Parkes (1998), o luto consiste na expressão de perdas significativas. Trata-se de um sentimento expresso frente a uma separação ou ruptura, que pode ser de alguém, de algum objeto, da condição financeira ou de um bem material; parte do corpo, dentre outros. Pode ser inclusive de ordem sentimental, como: proteção, amor, vitalidade, beleza etc. O luto é a fase da expressão dos sentimentos decorrentes da perda, a qual se demonstra por choque, desejo, desorganização; é a fase de aprender e estabelecer novas concepções sobre o mundo, favorecendo investimentos pessoais.

Quando o vínculo afetivo se quebra, surgem a dor e outros sentimentos associados. Trata-se de uma reação emocional podendo envolver correlatos fisiológicos e sociais. No geral, a duraçáo e intensidade desse processo seriam proporcionais à dimensão e significado da perda (KOVÁCS, 1996; KÜBLERROSS, 1997; PARKES, 1998).

Lima (2006) refere que a reação subsequente a uma perda é o luto, e que para haver o luto antes é necessário haver uma perda significativa. Nesse sentido, o luto abrange a expressão dos sentimentos do pesar no meio externo e o processo de elaboraçáo vivido devido às perdas.

Segundo Parkes (1998, p. 22), “[...] o luto pode não causar dor física, mas causa desconforto e geralmente altera funçóes". O luto pode promover inúmeras implicaçôes para a saúde global da pessoa, dentre elas estão a dificuldade em manter a vida laborativa, a execução das atividades da vida diária, o autocuidado, a participaçáo nas atividades de lazer etc. Tal condição pode envolver muita tristeza e decorrer em grande sofrimento por quem a vivencia.
Bromberg (2000) afirma que, nesse período, os enlutados convivem com o sentimento de desinteresse, afastamento e desânimo pelas atividades ocupacionais do mundo externo. Manifestam sentimentos de tristeza, isolamento, presença de humor depressivo, entre outros. Há também pessoas que apresentam uma hiperatividade na execução de suas ocupaçôes, envolvendo-se ainda mais em suas atividades. Ainda segundo a autora, nas condiçóes de luto:

Os sentimentos que acompanham a perda são intensos e afetam emoçóes, corpos e vidas, por um longo período, compreende uma tristeza preocupante, associada com momentos de angústia, raiva, saudade, medo e ausência (BROMBERG, 2000, p. 24).

Para Jasmim, após a perda, houve dificuldade de engajamento nas ocupaçóes do dia a dia. Jasmim vivenciou isolamento e sentimentos de tristeza, desinteresse em interagir com outras crianças e frequentar espaços, como a brinquedoteca. $\mathrm{O}$ sentimento de perda era algo novo, visto que o acidente aconteceu de forma inesperada, trazendo intenso sofrimento pela perda dos cabelos, pelo afastamento dos papéis ocupacionais e o longo período de hospitalização. Jasmim apresentou dificuldade para a elaboração do seu processo de luto. Apresentou sentimentos de desinteresse, afastamento e desânimo pelas atividades ocupacionais do mundo externo, atitudes que eram percebidas no dia a dia no hospital, o que implica no grupo social e familiar ao qual está inserida, mobilizando-os diante da nova situação.

O luto é todo processo pós-perda. Nesse contexto, o luto pode ser entendido como uma fase de expressão dos sentimentos decorrentes da perda, a qual se demonstra por choque, desejo, desorganização e organizaçáo. Quando o vínculo afetivo se quebra, surgem a dor e outros sentimentos associados. Trata-se de uma reaçáo emocional, podendo envolver correlatos fisiológicos, sociais, ocupacionais, entre outros. No geral, a duração e intensidade desse processo seriam proporcionais à dimensão e significado da perda.

O luto, entendido como uma constelação de reaçóes psíquicas, conscientes e inconscientes, e ainda sociais e ocupacionais, a uma perda significativa, é uma experiência complexa que transcende o âmbito individual, repercutindo no grupo social, incluindo também os profissionais que prestam cuidados (CORRÊA, 2009, 2010).

Para Jasmim, o processo de luto não surgiu logo após o escalpelamento, mas posteriormente às vivências das consequências físicas, psicoemocionais e ocupacionais do acidente, onde houve inúmeras 
perdas: cabelo, saúde, distanciou-se do convívio com outras crianças, apresentou desinteresse em realizar o brincar e em desempenhar suas atividades de vida diária ${ }^{6}$, dentre outras modificaçóes no viver.

A Terapia Ocupacional no cuidado a uma criança em situação de escalpelamento: percepçóes sobre uma experiência com o brincar nas condiçóes de perda e luto

Para Castro (2004), na formação do terapeuta ocupacional, estudos, discussões, observaçôes, vivências e práticas preparam para um encontro que valorize a expressão e o acolhimento, as singularidades, o revelar rupturas, demandas, entre outras especificidades. Nesse sentido, uma atividade profissional é estruturada continuamente, de forma dinâmica e a cada encontro. Nesse estudo, buscou uma comunicação simples e próxima do contexto cultural da criança. Por meio do brincar, foi possível resgatar experiências anteriores e estabelecer um espaço para a expressão das sensaçóes vivenciadas por Jasmim, possibilitando-se desvelar expressóes de sentimentos como tristeza, medo, ansiedade, as sensaçóes decorrentes dos procedimentos invasivos, dentre outros.

O brincar é uma atividade prazerosa e espontânea que envolve oportunidades de descoberta, criatividade, autoexpressão, possibilitando o desenvolvimento da coordenação motora, da cognição, da linguagem e das interaçóes sociais, assim como contribui para o desenvolvimento da criança.

Durante o brincar, Jasmim lembrava-se das brincadeiras com o irmão, da disputa com ele pelos brinquedos, de quando passava horas tomando banho de rio, entre outras situaçóes. Para Jasmim, o brincar funcionou como recurso para expressão das perdas, entre as quais destacam-se o afastamento da família, da escola, de seus brinquedos, a perda dos cabelos, $\mathrm{da}$ autonomia e independência. Entende-se que esses momentos eram uma oportunidade para que Jasmim pudesse recordar experiências que lhe faziam bem, que a aproximavam de sua vida, das pessoas queridas e próximas. Expressava situaçóes ainda não reveladas verbalmente. Compreende-se que o brincar é algo espontâneo, singular e intrinsecamente criativo, pois se baseia no interesse da criança e não nas expectativas terapêuticas.

Nesse sentido, essa experiência possibilitou que a criança pudesse escolher com o que gostaria de brincar, favoreceu o estabelecimento das relaçóes em que Jasmim também podia escolher os modos de agir, expressar e estar naquele momento da internação, permitiu a expressão de desejos e afliçôes.
Jasmim podia manifestar-se criativamente e brincar espontaneamente, sem regras.

A existência de um espaço destinado ao brincar dentro de um hospital reflete o cuidado com o bem-estar global da criança internada, reafirmando a necessidade, o desejo e as demandas quanto ao engajamento ocupacional. Também contribui para a desmistificação de que ambiente hospitalar seja, comumente, percebido como hostil, um espaço para a inatividade. Enfim, o hospital também possibilitaria experienciar sensaçóes boas e agradáveis.

Quando as pessoas experienciam situaçóes de hospitalização, essa condição pode alterar diretamente o processo de recuperaçáo. Nesse sentido, as intervenções visavam a promoção de condiçôes favoráveis à saúde, devendo incentivar e organizar estratégias que atendiam às necessidades das pessoas internadas, considerando aspectos psíquicos, pedagógicos e socioculturais, entre outros, da criança e de sua família.

Espaços como o da brinquedoteca vêm proporcionar um lugar para que o brincar seja tratado como atividades voluntárias, livres, onde a criança manifesta desejos; sua realidade, através do "faz de conta", mostra o jogo como uma ação que se processa e existe no interior de um campo e tempo previamente delimitado e determinado, possibilitando à criança usar sua criatividade para elaborar suas próprias açôes e regras de convivências, pois desperta a criatividade, o raciocínio, o significado de ganhar e perder e o convívio com outras crianças no mesmo grupo (CUNHA, 2001).

Para Motta e Enumo (2004), a introdução do brincar na instituição hospitalar figura como um importante instrumento terapêutico, possibilitando a reorganização da percepção da criança por permitir a expressão de seus sentimentos e emoçóes, ajudando-a a enfrentar com segurança a ansiedade provocada pela situação de hospitalização, uma vez que o brincar é o processo básico de criação, próprio da natureza humana e constituinte da identidade pessoal.

Segundo Tosta (2009), brincar é a atividade mais importante da vida da criança e é crucial para o seu desenvolvimento motor, emocional, mental e social. É a forma pela qual ela se comunica com o meio social em que vive, expressa ativamente seus sentimentos, ansiedade e frustraçóes. Por meio do brincar, em um evento onde é sujeito passivo, ela transforma-se em investigador e controlador ativo, e pode adquirir o domínio da situação.

O brincar é a forma natural de manifestação, autoconhecimento e exploração do mundo, uma vez que subsidia a assimilação das situaçôes vividas ao 
mesmo tempo em que se constitui como um meio seguro para a expressão da angústia, medo e sensação de desamparo que caracterizam, muitas vezes, as experiências de algumas crianças hospitalizadas (MOTTA; ENUMO, 2004).

Neste estudo, Jasmim pôde "brincar de médico" com uma boneca que convencionou estar doente. A boneca precisaria de procedimentos médicos que foram realizados pela criança, permitindo que antecipasse suas dúvidas e receios por meio da vivência, de forma a minimizar os seus temores durante os procedimentos reais, permitindo à criança reproduzir o que estava sentindo e reelaborar seu processo de doença.

A proposta dessa brincadeira é conhecida como ensaio comportamental, que, segundo Pfeifer e Mitre (2008), refere-se à terminologia usada na área da psicologia. Consiste em estimular a criança a reproduzir os procedimentos ou as situaçóes utilizando brinquedos ou o próprio terapeuta, como forma de treinar estratégias para o enfrentamento. Essa técnica se assemelha ao brinquedo terapêutico, em que a criança é encorajada a realizar, em bonecos, os procedimentos pelos quais vai passar, bem como a manusear equipamentos e materiais (de brincadeira ou reais, se forem seguros para a criança), como termômetro, seringas, entre outros.

As vivências oferecidas à criança permitiram a expressão de sentimentos como raiva, medo e desamparo em relação à hospitalização e ao acidente. Entende-se que o escalpelamento trouxe várias perdas para Jasmim. Desse modo, o brincar foi utilizado como mediador na comunicação entre a criança e a terapeuta ocupacional com o objetivo de compreender as situaçóes enfrentadas por Jasmim, bem como as singularidades e implicaçôes do seu processo de adoecimento e hospitalização.

Utilizando-se o brincar na prática dessa pesquisa, percebeu-se também que a criança pode expressar algumas reaçóes decorrentes de acontecimentos de sua vida, como o abandono do pai e, principalmente, o acidente que ocasionou o escalpelamento. Em alguns momentos, a paciente demonstrou vergonha em aproximar-se de outras crianças, funcionando o brincar como estratégia para a expressão dessas reaçóes e aproximação com os outros pacientes.

No contexto hospitalar, o brincar pode ser usado como alternativa de intervenção, instrumento de comunicação e de acesso aos comportamentos da criança. $\mathrm{O}$ brincar auxiliou na socialização e interação da paciente com outras crianças, permitindo que a mesma pudesse sair do isolamento de sua enfermaria e enfrentar a realidade de acordo com a sua nova situação.

$\mathrm{Na}$ terapia ocupacional, o brincar é visto como uma ocupação infantil fundamental e em geral é utilizado como recurso terapêutico para promover o desenvolvimento de habilidades físicas, cognitivas, emocionais, relacionais e sociais (PFEIFER; MITRE, 2008). No caso de Jasmim, o brincar proporcionou a oportunidade de lidar com sentimentos como medo, angústia e ansiedade, possibilitando que saísse da passividade que, geralmente, ocorre com a hospitalização. O brincar também auxiliou na aprendizagem de habilidades e interesses da criança para realizar suas futuras escolhas.

Teixeira (2003) afirma que a criança necessita apenas ser auxiliada para ter a oportunidade de descobrir e aprender, interagindo com o ambiente, buscando a propriedade e função dos objetos, manipulando e transformando-os. Nessa perspectiva, o profissional de saúde passa a ser compreendido como aquele que, além da assistência no intuito de restabelecer a saúde da criança, numa concepçáo de integralidade, também pode valorizar o ser humano em sua individualidade, compreendendo suas reais necessidades a partir de uma atitude de acolhimento (PFEIFER; MITRE, 2008). Com Jasmim, pôde-se perceber a necessidade de enfatizar não somente o seu comprometimento físico, mas também suas ocupaçóes.

Neste estudo, entende-se que ocupação refere-se a todas as açóes que preenchem o tempo das pessoas e dão sentido à sua vida. Essas atividades são denominadas áreas de desempenho, que podem ser divididas em atividades diárias, laborativas e produtivas e atividades de lazer e diversão (MELLO; MANCINI, 2007). A concepção integral da criança pelos profissionais da saúde, especialmente pelo terapeuta ocupacional, implica na atenção à criança como ser com suas ocupaçóes, que caracterizam suas necessidades e habilidades. Proporcionar à criança um olhar além de seu quadro clínico é contribuir para seu desenvolvimento, no que diz respeito aos aspectos biológicos, psicológicos, sociais, ocupacionais, entre outros, e permitirá realizaçóes e escolhas ao longo da vida.

Por entender que o envolvimento em ocupaçóes como o trabalho, o lazer, atividades da vida diária (AVDs) e outras referentes à participação em comunidade está relacionado à condição de saúde cognitiva, física, psicossocial e contextual da pessoa, destacam-se algumas especificidades do trabalho do terapeuta ocupacional na assistência às pessoas que sofreram perdas significativas. 
Ressalta-se o olhar singular desse profissional sobre o processo de luto, uma vez que a pessoa enlutada pode afastar-se de suas ocupações, inclusive daquelas relacionadas aos cuidados destinados à manutenção de sua vida - cuidados pessoais, além de geralmente manifestar baixa autoestima, capacidade diminuída de pensar e concentrar-se, desinteresse e afastamento das atividades ocupacionais cotidianas (SOUZA; CORRÊA, 2009; CORRÊA, 2010). Desse modo, contextualiza-se que essas demandas devem ser valorizadas pelo profissional de saúde, no qual o terapeuta ocupacional se destaca, por intervir através da ação humana.

Em relação a Jasmim, entende-se que, além dos efeitos da hospitalizaçáo e o afastamento do seu cotidiano, sua atividade ocupacional, que era o brincar, também estava alterada em decorrência das modificaçôes causadas pelo acidente. Nesse contexto, a terapeuta ocupacional buscava compreender e prestar assistência para amenizar essa sintomatologia, utilizando o brincar livre como instrumento.

\section{Considerações finais}

Com base nas intervençôes deste estudo, pode-se considerar que Jasmim teve a sua vida ocupacional totalmente modificada pelo longo período de hospitalização vivenciado. Para a criança, a terapia ocupacional buscou compreendê-la em sua totalidade, sendo que o processo de terapia ocupacional ocorreu enfocando-se no brincar, possibilitando a expressão das perdas advindas do acidente de maneira a ressignificá-las para melhora da qualidade de viver. Os encontros favoreceram o engajamento da criança em atividades que fossem significativas para ela, através da livre escolha, proporcionando a sua participação social.

Nos primeiros contatos com a criança, foi possível perceber que ela apresentava distanciamento da equipe de saúde do hospital, demonstrando-se tímida, envergonhada e temerosa com os procedimentos. Após os encontros, a criança mostrou-se mais adaptada ao contexto da hospitalização, à rotina de curativos e aos profissionais de saúde.

Através do atendimento de terapia ocupacional, pôde-se estabelecer vínculo com a paciente, o que foi possível por meio da proposta de basearem-se os atendimentos de acordo com as necessidades desta. Esse vínculo foi de significativa importância para a obtenção dos resultados terapêuticos, visto que a paciente sentiu segurança em expressar sentimentos como tristeza, medo e angústia. A terapia ocupacional trouxe várias contribuiçóes para a paciente, auxiliando-a a retornar ao seu principal papel ocupacional - brincar.

Para a pesquisadora e terapeuta ocupacional, o estudo contribui para o crescimento pessoal através da troca de experiências com a criança. Nesse sentido, acredita-se que esta pesquisa poderá contribuir para com os profissionais terapeutas ocupacionais no sentido de ilustrar uma das possibilidades do cuidado em situações de intenso sofrimento, destacando as perdas significativas advindas desse contexto em que a criança é afastada de sua rotina, de seu lar, de sua família e amigos, caracterizando que a intervenção deve basear-se na totalidade do ser, preservando-se a singularidade e individualidade.

Esse trabalho também vem contribuir no sentido de fornecer subsídios teórico-práticos para futuros estudos, bem como para auxiliar na prática profissional, pois os resultados apresentados aqui podem contribuir para a atuação do terapeuta ocupacional na assistência hospitalar a crianças escalpeladas, e nos demais casos em que há perdas significativas, por intermédio do brincar.

No sentido da exploração do tema, poucas referências bibliográficas são encontradas, foi realizado esclarecimento acerca da temática a fim de comunicar à sociedade a necessidade de discussão sobre o assunto para que se tornem possíveis a diminuiçáo ou a não ocorrência de acidentes por escalpelamento. Desse modo, faz-se um convite aos demais pesquisadores para que invistam em pesquisas nessa área, pois a produçáo científica brasileira abordando essa temática ainda é muito escassa.

Através da pesquisa pode-se concluir que o escalpelamento ocasiona perdas significativas em suas vítimas, tanto pelas modificações corporais quanto pelo distanciamento de sua rotina. $\mathrm{O}$ que ocasiona intenso sofrimento, principalmente para a criança, onde a hospitalização acontece de forma inesperada, descontextualizando-a, repercutindo em um ambiente desfavorável ao seu desenvolvimento.

\section{Referências}

AMERICAN OCCUPATIONAL THERAPY ASSOCIATION - AOTA. Uniform Terminology - third edition: application to practice. The American Journal of Occupational Therapy, v. 48, n. 11, p. 1055-1059, Nov/ Dec 1994. http://dx.doi.org/10.5014/ajot.48.11.1055

BOWLBY, J. Angústia e separação: revisão da literatura. In: BOWLBY, J. Separação: angústia e raiva. 2. ed. São Paulo: Martins Fontes, 1993. p. 37-38.

BRITTO, C. B. L. et al. Escalpelamento na população amazônica. Revista Paraense de Medicina, Belém, v. 18, n. 1, p. 30-35, jan./mar. 2004. 
BROMBERG, M. H. P. F. A psicoterapia em situaçóes de perdas e luto. São Paulo: Psy II, 1994.

BROMBERG, M. H. P. F. Psicoterapia em situaçóes de perdas e luto. Campinas: Livro Pleno, 2000.

CARVALHO, A. M.; BEGNIS, J. G. Brincar em unidades de atendimento pediátrico: aplicações e perspectivas. Psicologia em Estudo, Maringá, v. 11, n. 1, p. 109-117, 2006. http://dx.doi.org/10.1590/S1413-73722006000100013

CASTRO, E. D. Dança, Corporeidade e Saúde Mental: experimentações em Terapia Ocupacional. In: ARCURI, I. (Org.). Arteterapia de Corpo e Alma. São Paulo: Casa do Psicológo, 2004. v. 1, p. 239-278.

CASTRO, E. K. Psicologia pediátrica: a atenção à criança e ao adolescente com problemas de saúde. Revista Psicologia: ciência e profissão, Brasília, v. 27, n. 3, p. 396-405, jul./set. 2007. http://dx.doi.org/10.1590/ S1414-98932007000300003

CHIZZOTTI, A. Pesquisa em ciências humanas e sociais. 5 ed. Sáo Paulo: Cortez, 2001.

CONSELHO NACIONAL DE SAÚDE - CNS. Resolução $\mathrm{n}^{\circ}$ 196. Diretrizes e normas regulamentadoras sobre pesquisa envolvendo seres humanos. Brasília: CNS, 1996.

CORRÊA, V. A. C. A expressão do pesar nas atividades ocupacionais quando alguém querido morre. 2009. 107 f. Dissertação (Mestrado em Psicologia)-Instituto de Filosofia e Ciências Humanas, Universidade Federal do Pará, Belém, 2009.

CORRÊA, V. A. C. Luto: intervenção em Terapia ocupacional. Belém: Editora Amazônia, 2010.

CUNHA, N. H. S. Brinquedoteca, um mergulho no brincar. 3. ed. São Paulo: Vetor, 2001.

DICIONÁRIO MÉDICO. Escalpo. [s.1.]: DicionárioMédico.com, 2008. Disponível em: <http:// www.xn--dicionriomdico-0gb6k.com/escalpo.html>. Acesso em: 15 set. 2010.

FEDERAÇÃO DAS ASSOCIAÇÓES DE MUNICIPIOS DO ESTADO DO PARÁ - FAMEP. Belém: FAMEP, 2000. Disponível em: <http://www.famep. org.br/famep/dado_geral/mumain.asp $>$. Acesso em: 10 ago. 2010.

FERREIRA, A. B. H. Minidicionário Aurélio da Língua Portuguesa. 7. ed. São Paulo: Positivo, 2008.

FONTES, R. S. A escuta pedagógica à criança hospitalizada: discutindo o papel da educação no hospital. Revista Brasileira de Educaçāo, Rio de Janeiro, n. 29, p. 119-139, 2005. http://dx.doi.org/10.1590/ S1413-24782005000200010

GRILO, A. M. Os Modelos de Saúde: suas implicaçóes na humanização dos serviços de saúde. In: CONGRESSO HÍSPANO - PORTUGUÊS DE PSICOLOGIA, 2., 2004, Lisboa. Anais. Lisboa: Iber Psicologia, 2004. p. 1-8.

KOVÁCS, M.J. A morte em vida. In: BROMBERG, M. P. F.; CARVALHO, M. M. J.; CARVALHO, V. A. Vida e morte: laços de existência. São Paulo: Casa do Psicólogo, 1996, p. 12-33.

KÜBLER-ROSS, E. Sobre a morte e o morrer. 8 ed. São Paulo: Martins Fontes, 1997.
LIMA, A. Recriando o espaço e a dimensão ocupacional da criança no ambiente hospitalar. Recife: UFPE, 2006. Disponível em: <http://www.proext.ufpe.br/cadernos/ saude/crianca.htm>. Acesso em: 04 nov. 2009.

LINDQUIST, I. A criança no hospital: terapia pelo brinquedo. São Paulo: Scritta, 1993.

MARCO, M. A. A face humana da medicina: do Modelo Biomédico ao Modelo Biopsicossocial. São Paulo: Casa do Psicólogo: 2003.

MARTINS, J., BICUDO, M. A. V. A pesquisa qualitativa em Psicologia: fundamentos e recursos básicos. 3. ed. São Paulo: Centauro, 2003.

MELlO, M. A. F.; MANCINI, M. C. Avaliação das atividades da vida diária e controle domiciliar. In: CAVALCANTI, A; GALVÃO, C. Terapia Ocupacional: fundamentos e prática. Rio de Janeiro: Guanabara Koogan, 2007. p. 49-54.

MINAYO, M. C. S. O desafio do conhecimento: pesquisa qualitativa em saúde. São Paulo: Hucitc; Rio de janeiro: ABRASCO, 2008.

MOTTA, A. B.; ENUMO, S. R. F. Brincar no hospital: estratégia de enfrentamento da hospitalização infantil. Psicologia em Estudo, Maringá, v. 9, n. 1, p. 19-28, 2004. http://dx.doi.org/10.1590/S1413-73722004000100004

MOTTA, M. A contribuição da fisioterapia no tratamento de vitimas de escalpelamento. [s.l.: s.n.], 2003. Disponível em: <http://www.elden.hpg.ig.com.br/saude>. Acesso em: 04 nov. 2009.

NUNES, S. O. V. Alterações neuroquímicas da depressão. In: BRANDÃO, M. Z. S. et al. (Org.). Sobre Comportamento e Cognição: Clínica, Pesquisa e Aplicação. Santo André: ESETec Editores Associados, 2003. v. 12, p. 30-41.

OLIVEIRA, S. Tratado de Metodologia Cientifica: Projetos de Pesquisa, TGI, TCC, Monografias, Dissertações e Teses. 2. ed. São Paulo: Pioneira, 2000.

OLIVEIRA, M. M. Como fazer pesquisa qualitativa. Petrópolis: Vozes, 2007.

OTHERO, M. B. Terapia ocupacional: práticas em oncologia. São Paulo: Roca, 2010.

PARÁ. Fundação Santa Casa de Misericórdia do Pará. Guia técnico do Programa de Atendimento Integral às Vitimas de Escalpelamento - PAIVES. Belém: FSCMPA, 2008.

PARKES, C. M. Luto: estudos sobre a perda na vida adulta. São Paulo: Summus, 1998.

PFEIFER, L. I.; MITRE, R. M. A. Terapia ocupacional, dor e cuidados paliativos na atenção à infância. In: DE CARLO, M. M. R. P.; QUEIROZ, M. E. G. Dor e Cuidados Paliativos - Terapia ocupacional e interdisciplinaridade. São Paulo: Roca, 2007. p. 258-287.

ROCHA, E. F.; BRUNELLO, M. I. B. Avaliação qualitativa em Terapia Ocupacional: princípios, métodos e técnicas de coleta de dados. In: CAVALCANTI, A.; GALVÂO, C. Terapia Ocupacional: fundamento e prática. Rio de Janeiro: Guanabara Koogan, 2007. p. 45-48. 
SILVA, S. A. A pessoa enferma e a hospitalização: o enfermeiro nesse contexto. 1992. 110 f. Dissertação (Mestrado em Enfermagem)-Universidade Federal do Rio de Janeiro, Rio de Janeiro, 1992.

SILVA, J. C. O Rio, A Comunidade e o Viver. 2000. $181 \mathrm{f}$. Tese (Doutorado em Geografia Humana)-Universidade de São Paulo, São Paulo, 2000.

SOCIEDADE BRASILEIRA DE CIRURGIA DERMATOLÓGICA - SBCD. Lista de procedimentos. São Paulo: SBCD, 2008. Disponível em: <http://www. sbcd.org.br/procedimentos.php?id=100>. Acesso em: 12 jun. 2010.

SOUZA, A. M. CORRÊA, V. A. C. Compreendendo o pesar do luto nas atividades ocupacionais. Revista do NUFEN, Belém, v. 1, n. 2, p. 131-148, ago./nov. 2009.

TAKATORI, M.; OSHIRO, M.; OTASHIMA, C. O hospital e a assistência em Terapia Ocupacional com a população infantil. In: DE CARLO, M. M . R. P.; LUZO, M. C. M. Terapia Ocupacional: reabilitação física e contextos hospitares. São Paulo: Roca, 2004. p. 256-277.

TEIXEIRA, E. Terapia Ocupacional na reabilitação física. São Paulo: Roca, 2003.

TOSTA, R. M. A atividade lúdica da criança no contexto da internação hospitalar. São Paulo: PUC-SP, 2007. Disponível em: <www.pucsp.br/ clinpsic/tosta.html> Acesso em: 30 dez. 2009

TURATO, E. R. Tratado da metodologia da pesquisa clinico-qualitativa. São Paulo: Vozes, 2003. p. 45-65.

VENTURA, M. M. O estudo de caso como modalidade de pesquisa. Revista SOCERJ, Rio de janeiro, v. 20, n. 5, p. 383-386, set./out. 2007.

YIN, R. Estudo de caso: planejamento e métodos. 2. ed. Porto Alegre: Bookman, 2001.

\section{Contribuição dos Autores}

Andreza Mourão Lopes: concepção do texto manuscrito, organizaçáo de fontes, coleta e análise dos dados, redação do texto. Victor Augusto Cavaleiro Corrêa: Orientação, revisão do trabalho.

\section{Notas}

${ }^{1}$ As comunidades ribeirinhas são povos que possuem seu modo de vida peculiar que as distingue das demais populaçóes do meio rural ou urbano. Para essas populaçôes o rio, o igarapé e o lago não são apenas elementos do cenário ou paisagem, mas algo constitutivo do modo de ser e viver do homem (SILVA, 2000, p. 27).

${ }^{2}$ Escalpo: pele e tecido subcutâneo da parte da cabeça coberta pelos cabelos (DICIONÁRIO MÉDICO, 2008).

${ }^{3}$ Denomina-se enxerto a um pedaço de pele retirada de uma área corpórea chamada área doadora e transferida a outra, a área receptora, e nessa área se restabelece assim um novo suprimento sanguíneo (SOCIEDADE..., 2008).

${ }^{4} \mathrm{O}$ município de Itaituba pertence a Mesorregião do Sudoeste Paraense e a Microrregião de Itaituba, possui uma população total de $94.750,00$ de habitantes e sua área é de $62.040,95 \mathrm{~km}^{2}$ representando 4,97\% do Estado, 1,61 \% da Regiāo e $0,73 \%$ de todo o território brasileiro (FEDERAÇÃO..., 2010).

${ }^{5}$ Salva-vidas é uma bóia ou aparelho para salvamento de náufragos (FERREIRA, 2008).

${ }^{6}$ Atividades de Vida Diária são as tarefas de automanutençáo, sendo inclusos 15 domínios: arrumar-se, higiene pessoal (oral, higiene no toalete e banho), cuidados com objetos pessoais, vestuário, alimentaçáo (comer e dar alimento), medicamento rotineiro, manutenção da saúde, socialização, comunicação, mobilidade, resposta de emergência e expressão sexual (AMERICAN..., 1994). 